\title{
КРИТЕРІАЛЬНІ ОЦІНКИ ВИБОРУ МОДЕЛЕЙ ШВИДКОДІЮЧИХ ЕЛЕКТРОННИХ ПРИСТРОЇв
}

\begin{abstract}
Анотація. Розроблені моделі і методи аналізу електронних інформаційно-комунікаційних засобів, що характеризуються високою швидкістю, що відображають як схемну, так і морфологічну структуру швидкодіючих компонентів сучасних спеціалізованих комп'ютерних систем. Запропонована модель відображае фізичні процеси, що працюють в широкому діапазоні частот до 10 терагерц і вище. Застосування нових принципів і технологій, в тому числі біо- і нанотехнологій, розробка монолітних інтегральних схем призвели до відставання технологій проектування від технологій їх експериментальних досліджень і виготовлення. Отримані результати дозволяють оцінити електромагнітні взаємодії як неавтономних компонентів, так і їх комунікаційних структур в рамках монолітних інтегральних схем та розширити можливості сучасних систем автоматизованого проектування наноелектроніки.
\end{abstract}

Ключові слова: моделювання в наноелектроніці, високочастотна електроніка, електромагнітні перешкоди; САПР.

Sliusarenko Volodymyr, Kudria Volodymyr

Odessa Polytechnic State University

\section{CRITERIA FOR THE SELECTION OF MODELS OF HIGH-SPEED ELECTRONIC DEVICES}

Summary. Modern CAD systems of electronics are characterized by a number of disadvantages, among which the most significant is an insufficiently clear display of the morphological characteristics of high-frequency electronic means. In addition, despite the large number of different methods for analyzing electrical circuits, the analysis packages do not focus on choosing the optimal one. The paper develops models and methods for modeling electronic information and communication tools characterized by high speed, reflecting both the circuit and morphological structure of high-speed components of modern specialized computer systems. This type of model should reflect physical processes operating in a wide frequency range up to 10 terahertz or higher. The application of new principles and technologies, including bio- and nanotechnologies, and the development of monolithic integrated circuits have led to a lag in design technologies from the technologies of their experimental research and manufacturing. The results of the study allow us to evaluate the electromagnetic interactions of both non-autonomous components and their communication structures within monolithic integrated circuits and expand the capabilities of modern computer-aided design systems for nanoelectronics. Indeed, even now the ratio of Design Technologies and production process technologies in nanoelectronics reaches approximately 50 to 1 . within the framework of existing physical and mathematical models that do not take into account the integral effect of physical phenomena in nanoelectronics, this ratio will only increase. It so happened that the developed packages of analysis of electronic means: Spice, MicroCap, OrCAD, MultiSim, atium Design, Proteus, ANSYS, which have received worldwide recognition, are characterized by at least two disadvantages: first, process modeling, that is, such types of analysis as DC, AC, TA, do not focus on morphological and, at the same time, on the topological properties of an electrical circuit (EC). Secondly, linearization of the characteristics at the operating point and replacement of the components at this point with linear ones does not allow us to correctly reproduce the simulation of nonlinear components of the EC in the "large and medium signal"mode. It can be argued that the lion's share of low-quality monolithic integrated circuits produced reaches $50 \%$ due to the use of inadequate physical and mathematical models of the mentioned CAD electronics. Thus, the aim of this work is to develop models and methods of analysis that reflect not only the topological, but also the morphological properties of the design object when taking into account electromagnetic interference of energy and information transmission paths in a monolithic integrated circuit.

Keywords: modeling in nanoelectronic, high-frequency electronics, electromagnetic interference, CAD.

$\Pi^{2}$ остановка проблеми. Сучасні САПР електроніки характеризуються низкою недоліків, серед яких найбільш вагомим $є$ недостатньо чітке відображення морфологічних характеристик високочастотних електронних засобів на етапі їх проектування. Окрім того незважаючи на велику кількість різноманітних методів аналізу електричних кіл САПРи, як правило використовують лише один 3 них, найчастіше - це метод змінних стану. При цьому до уваги не береться співвідношення між кількістю гілок та вузлів, незважаючи на морфологічні характеристики ЕК. Разом з тим вибір оптимальної моделі та відповідно оптимального методу дозволив би суттево скоротити, як процес проектування так i технологічний процес виготовлення монолітних інтегральних схем (MIC). Усуненню цих недоліків і присвячена тема даного дослідження

Аналіз останніх досліджень і публікацій. Дане питання розглядалося багатьма авторами [1-5], серед яких найбільш вагомі результати були отримані: Тозоні О.В., Князь А.I., Чуа Л.О., Пен-Мен-Лін. Разом з тим розрив між виробничими процесами та моделями, що їх обумовлюють продовжуе зростати. Як правило, виробництво багатоядерних процесорів, контролерів та програмованих логічних схем в більшій мірі спирається на пошук оптимальних конструкцій 
через емпіричні експериментальні дослідження, а ніж на математичні моделі фрізичних процесів. Останне призводить до зростання непродуктивних виробничих витрат.

Усунення цього недоліку, на що спрямоване дослідження, $є$ достатньо актуальною проблемою сьогодення Дійсно, вже зараз [3; 4] співвідношення технологів проектування і технологів виробничих процесів в наноелектроніці досягає приблизно 50 до 1. В рамках існуючих фізико-математичних моделей, що не враховують інтегрального ефректу фрізичних явищ в наноелектроніщі, це співвідношення буде тільки збільшуватися.

Виділення нерозв'язаних раніше частин загальної проблем. Так склалося, що розроблені пакети аналізу електронних засобів: Spice, MicroCap, OrCAD, MultiSim, Atium Design, Proteus, ANSYS, які отримали світове визнання, - характеризуються як мінімум двома недоліками: по-перше, моделювання процесів, тобто такі види аналізу, як DC, AC, TA, не фокусуються на морфологічних i, в той же час, на топологічних властивостях електричного кола (ЕК). По-друге, лінеаризація характеристик в робочій точці і заміна в цій точці складових на лінійні не дозволяє коректно відтворити моделювання нелінійних складових ЕК в режимі «великого і середнього сигналу». Можна стверджувати, що левова частка неякісних монолітних інтегральних схем, що випускаються, досягає 50\% через використання неадекватних фрізико-математичних моделей згаданої САПР електроніки [3].

Таким чином, метою даної роботи $є$ розробка моделей і методів аналізу, що відображають не тільки топологічні, а й морфологічні властивості об'єкта проектування при обліку електромагнітних перешкод шляхів передачі енергії та інфрормації в монолітній інтегральній схемі.

Оскільки забезпечення енергетичної автономності дерев комунікаційних структур і самих неоднорідностей нанобази не може бути досягнуто шляхом їх екранування, без таких алгоритмів проектування і аналіз високошвидкісних електронних продуктів проблематичний.

Виклад основного матеріалу. У класичному варіанті будь-яке ЕК може бути представлене у вигляді системи. Елементами системи є компоненти, що виконують певні фрункціональні перетворення індрормаційних сигналів, і сукупність зв'язків між елементами системи, яка називається комунікатором. На відміну від компонента, призначення комунікатора полягає в миттевій передачі інформащійних сигналів без зміни їх характеристик, тобто форми і рівня енергії. На ранньому етапі розвитку електроніки, який характеризувався відносно низькою продуктивністю (швидкістю) ЕК, модель у вигляді набору класичних законів Кірхгофра і компонентних рівнянь була цілком достатньою. Але 3 ростом комп'ютерних систем, що досягають $148,6\left(10^{\mathrm{E}+15}\right)$ операцій 3 плаваючою комою в секунду [4], і рівнем технологічної досконалості, що досягає 10...40 нанометрів, класична модель не відповідає вимогам часу. Основним недоліком класичної моделі є нехтування вимогами як внутрішньої, так і зовнішньої електромагнітної сумісності (ЕMC), а саме правильним урахуван- ням електромагнітних зв'язків дерев і ланцюгів комунікатора.

Подолання протиріччя між вимогою підвищення продуктивності і зниження електромагнітного впливу комунікатора в міс може бути запропоновано в моделі EK, яка увібрала б в себе як елементи класичної теорії, які добре описують топологію, так і елементи електродинаміки з ії здатністю моделювати морфологічні особливості конструкції ЕК.

Саме на межі теорії електричних ланщюгів і теорії електродинаміки можна розробити математичні моделі, що забезпечують нові технологічні прориви в зниженні напрямків дозволу, енергії на обробку бітів інформації, підвищенні продуктивності і щільності основних елементів на одинищю обсягу монолітних інтегральних схем.

Подолання протиріччя між класичними моделями синтезу та аналізу MIC та вимогами їх виробництва лежить у площині Доповнення класичної теорії ЕК елементами теорії електромагнітного поля з точки зору розрахунку потоків векторів електричної та магнітної індукції через задані поверхні гіпотетичної конструкції комунікатора міс. Напрямки розробки адекватних моделей високочастотних електричних ланцюгів, заземлених електродинамічним способом, певною мірою відображають специфіку проектування нанотехнологічної електроніки.

Розробка MIC повинна Ірунтуватися на інформації про френоменологічні характеристики найбільш елементарних (атомарних, композитних) компонентів. Однак будь-які внутрішні синергетичні процеси, що форомують зовнішні характеристики атомарних елементів системи, при застосуванні не є суттєвими. Виходячи з цих міркувань, ми побудуємо універсальну модель аналізу ЕК, яка відображала б фонкщії контурного i структурно-морфологічного характеру. Для цього уявіть, що ми маємо справу 3 реальним EK, Початкова схема і конструкція якого відомі. Виконуючи декомпозицію першого рівня, ми представляємо ЕК у вигляді двох складових компонентів: комунікатора і компонентів. Критерієм такого розбиття на першому ітераційному кроці може бути порівняння довжин електромагнітної хвилі, що випромінюеться в простір комунікатором і неавтономними компонентами, а також розмір міс в цілому. Комунікатор і компоненти характеризуються різними математичними моделями, які відображають ланцюговий (для компонентів) і хвильовий (для комунікатора) процеси відповідно.

Серед різних дескрипторів математичної моделі слід виділити дескриптори компонентів, дескриптори комунікаторів і дескриптори процесів ЕК.

\section{А. Дескриптори колпонентів}

Компоненти описуються: власною складовою назвою, яка може відображати клас компонентів і його індивідуальну специфікацію в цьому класі; параметрами, що мають певний фрізичний розмір (Ом, Генрі, Фарад); характеристиками (лінійними, параметричними, нелінійними, нелінійно-параметричними); морфологією, яка, в першу чергу, відображає геометричні розміри i електродинамічні параметри $(\varepsilon, \mu, \sigma)$ зовнішньої поверхні обсягу компонента та інші властивості, необхідні для експлуатаційних цілей; математична модель, що описує характеристики 
конкретної робочої зони, яка визначається вибором робочої точки і області дії сигналу. Слід зазначити, що при розробці математичної моделі нелінійних складових доцільно використовувати процедури усереднення за часом і лінеаризаціі характеристик.

У загальному випадку дескриптори компонентів слід описувати як скалярні або операторні матриці, які встановлюють відносини між вектором впливу і вектором реакції дескрипторів процесів. Морфологічні дані про компонент використовуються для вирішення завдань конструкторського і технологічного характеру: просторове або плоске розміщення; трасування; рівень енергетичної автономності; внутрішня і зовнішня електромагнітна, теплова, радіоактивна, радіаційна, біологічна сумісність та ін.

\section{В. Дескриптори колунікаторів}

Комунікатор включає в себе: провідники, друковані доріжки, екрани, Корпуси, роз'єми (порти введення-виведення), шлейсри, поверхні, ізолюючі дерева комунікатора один від одного, і так далі. Иого дескриптори також описуються матрицями, які пов'язують впливи і реакції на всіх полюсах i дугах комунікатора. Елементи матриць дескрипторів, для яких доцільно використовувати конкретну назву "електродинамічні параметри", визначаються шляхом вирішення крайових завдань електродинаміки. Слід зазначити, що вибір методу вирішення таких завдань також визначається співвідношенням розмірів: хвиля - комунікатор. Як правило, комунікатор має лінійну структуру, що міститься в гетерогенному середовищі.

\section{С. Дескриптори процесів}

Список фрізичних величин, що утворюють сукупність впливів і реакцій на полюсах (дугах) всіх компонентів і комунікатора, можна назвати дескрипторами процесів. Фізична природа цих дескрипторів обрана таким чином, щоб вони були універсальними 3 точки зору об'єднання різних етапів проектування в єдине ціле, з тим щоб сорормувати узагальнену для всіх етапів проектування математичну модель. Універсальна математична модель повинна встановлювати фрункціональні зв'язки між цими типами дескрипторів у вигляді узгодженої замкнутої системи рівнянь щодо дескрипторів процесів.

Побудова математичної моделі заснована на використанні трьох типів рівнянь

\section{A. рівняння колпонентів}

Рівняння, яке встановлює взаємозв'язок дескрипторів процесів на окремих компонентах, називається рівняннями компонентів. Набір всіх рівнянь ЕК може бути представлений одним 3 двох матричних рівнянь:

$$
\begin{aligned}
{[\mathbf{U}]_{m} } & =[\mathbf{Z}]_{m, m}[\mathbf{I}]_{m}+\left[\mathbf{U}_{\mathbf{0}}\right]_{m}, \\
{[\mathbf{I}]_{m} } & =[\mathbf{Y}]_{m, m}[\mathbf{U}]_{m}+\left[\mathbf{I}_{\mathbf{0}}\right]_{m},
\end{aligned}
$$

де $[\mathrm{U}]_{\mathrm{m}} \mathrm{i}[\mathrm{I}]_{\mathrm{m}}$ - стовпці матриці, елементами яких є дуги напруг $\dot{U}_{\alpha}, \forall \alpha=\overline{1, m}$ і полюси струмів $\dot{I}_{\alpha}, \forall \alpha=1, m$ компонентів; $\mathrm{m}$ - кількість полюсів або дуг всіх компонентів

$$
[\mathbf{U}]_{m}=\left[\begin{array}{c}
\dot{U}_{1} \\
\vdots \\
\dot{U}_{m}
\end{array}\right], \quad[\mathbf{I}]_{m}=\left[\begin{array}{c}
\dot{I}_{1} \\
\vdots \\
\dot{I}_{m}
\end{array}\right],
$$

Матриці $\left[\mathrm{U}_{0}\right],\left[\mathrm{I}_{0}\right]$ аналогічні (3) і характеризують додаткові напруги і струми, що підводяться до відповідних дуг і полюсів, які відтворюють дію внутрішніх джерел активних компонентів.

\section{В. Топологічні рівняння}

Цей тип рівняння відображає схему поєднання компонентів ЕК в цілому. Їх також можна назвати топологічними компонентно-комунікативними рівняннями. Для незалежних дерев

$$
[D]_{r, m}[\dot{I}]_{m}=\left[\dot{I}_{H}\right]_{r}
$$

де $[D]_{r, m}$ - матриця дерев, рядки якої відповідають номерам дерев, а стовпці - номерам $\alpha$ полюсів компонентів, двійкових елементів матриці, розрахованих на основі падіння $\alpha$-го полюса r-го дерева; $\left[\dot{I}_{H}\right]_{r}$ - матриця струмів, що не враховуються першим законом Кірхгофра [6] (зміщення і струм витоку в діелектричному середовищі).

Для незалежних ланцюгів

$$
[K]_{p, m}[\dot{U}]_{m}=\left[\dot{U}_{H}\right]_{m}
$$

де $[K]_{p, m}$ - контурна матриця, рядки якої відповідають номерам окремих контурів, а стовпці номерам полюсів складових, двійкових елементів матрищі, що обчислюються за падінням m-ї дуги р-го контуру; $\left[\dot{U}_{H}\right]_{m}-$ стовпець матриці напруги, заданої в кожному ланцюзі, який не враховується другим законом Кірхгофа [7] (індукційні напруги Фарадея і втрати в провідниках незалежних ланцюгів).

С. Рівняння комунікатора (лоробологічні)

Праві частини (4), (5), що відображають електромагнітні процеси, що не враховуються класичними законами теорії електричних ланцюгів

$$
\begin{gathered}
{\left[\dot{I}_{H}\right]_{r}=\left[\dot{I}_{G}\right]_{r}+\left[\dot{I}_{C}\right]_{r}} \\
{\left[\dot{U}_{H}\right]_{p}=\left[\dot{U}_{R}\right]_{p}+\left[\dot{U}_{L}\right]_{p}}
\end{gathered}
$$

де $\left[\dot{I}_{G}\right]_{r} ;\left[\dot{I}_{C}\right]_{r} ;\left[\dot{U}_{R}\right]_{p} ;\left[\dot{U}_{L}\right]_{p}$ - стовпщі матриці, виражені через електродинамічні параметри комунікатора. У свою чергу, електродинамічними параметрами є матричні коедіцієнти пропорційності між дескрипторами процесів і матрицями індукованих струмів від дерев і напруг в ланцюгах комунікатора. Рівняння (6) і (7) дозволяють побічно сформулювати завдання електродинаміки для визначення параметрів матриць комунікаторів.

Аналізуючи (1)... (7), легко отримати замкнуту систему рівнянь щодо дескрипторів процесів у вигляді

$$
[A]_{4 m, 4 m} X_{4 m}=B_{4 m}
$$

де $X_{4 m}$ - стовпець матриці невідомих струмів і напруг компонентів і комунікатора (дескриптори процесів); $[A]_{4 m, 4 m}, B_{4 m}$, матриці, елементи яких обчислюються через параметри компонентів і комунікатора.

Подання (8) у блочній фрормі

$$
[A]_{4 m, 4 m}=\left[\begin{array}{cccc}
A 11 & A 12 & A 13 & A 14 \\
A 21 & A 22 & A 23 & A 24 \\
A 31 & A 32 & A 34 & A 34 \\
A 41 & A 42 & A 43 & A 44
\end{array}\right] ; B_{4 m}=\left[\begin{array}{c}
B 1 \\
B 2 \\
B 3 \\
B 4
\end{array}\right]
$$

дозволяе розробляти різні класи задач аналізу монолітних інтегральних схем в широкому діапазоні частот, не змінюючи при цьому за- 
гальної структури математичного забезпечення систем проектування. Залежно від топологічної та морфологічної структури ЕК на основі (9) можна вибрати метод аналізу з мінімально можливою алгоритмічною обчислювальною складністю.

Висновки і пропозиції. У даному дослідженні розроблені математичні моделі високошвидкісних цифрових і аналогових електронних засобів, у тому числі нанотехнологічної електроніки, які відрізняються від існуючих можливостей цілеспрямованого комп'ютерного моделювання морфології з метою мінімізації шкідливого впливу на їх характеристики позасистемної електромагнітної взаємодії компонентів і комунікатора. Впровадження методів аналізу, заснованих на запропонованих моделях, сприятиме вдосконаленню технологій проектування і виготовлення монолітних інтегральних схем. Результати роботи мають перспективу впровадження в САПР високочастних електронних засобів.

\section{Список літератури:}

1. Чуа Л.О., Лин Пен-Мин Машинный анализ электронных схем: алгоритмы и вычислительные методы / пер. с англ. Москва : Энергия, 1980. 680 с.

2. Матметоды и моделирование в радиоэлектронике. URL: https://www.studmed.ru/science/radioelektronika/ mmethods (дата звернення: 10.04.2021).

3. Медіатусур. URL: http://www.youtube.com/watch?v=J-Ov3UtLsMo (дата звернення: 10.04.2021).

4. Технології майбутнього: наноматеріали та наноелектроніка. URL: http://www.youtube.com/watch?v= VDJA93OSXrI (дата звернення: 10.04.2021).

5. Князь А., Кудря В. Електродинамічно обгрунтовані схемні моделі параметричного відеопідсилювача. Радіотехніка. 1985. № 6. С. 87-88.

\section{References:}

1. Chua L.O., Lin Pen-Min (1980) Mashinnyy analiz elektronnykh skhem: Algoritmy i vychislitel'nye metody / per. s angl. Moscow: Energiya, 680 p.

2. Matmetody i modelirovanie v radioelektronike. URL: https://www.studmed.ru/science/radioelektronika/mmethods (accessed 10 April 2021).

3. Mediatusur. URL: http://www.youtube.com/watch?v=J-Ov3UtLsMo (accessed 10 April 2021).

4. Tekhnolohii maibutnoho nanomaterialy ta nanoelektronika. URL: http://www.youtube.com/watch?v=VDJA 930SXrI (accessed 10 April 2021).

5. Kniaz A., Kudria V. (1985) Elektrodynamichno obgruntovani skhemni modeli parametrychnoho videopidsyliuvacha. Radiotekhnika, no. 6, pp. 87-88. 